\title{
COMPARISON OF HAEMODYNAMIC STABILITY WITH 0.5\% AND 0.75\% HYPERBARIC BUPIVACAINE DURING SPINAL ANAESTHESIA IN WOMEN UNDERGOING CAESAREAN SECTION
}

\author{
Hina Iftikhar, Aneel Aslam*, Habib Ur Rehman, Zulfiqar Ali, Mohammad Ali Abbass, Zulfiqar Haider \\ Combined Military Hospital Multan/National University of Medical Sciences (NUMS) Pakistan, *Karachi Institute of Medical Sciences, Karachi Pakistan
}

\begin{abstract}
Objective: To compare the effect of $0.5 \%$ and $0.75 \%$ hyperbaric Bupivacaine on haemodynamic stability in terms of mean systolic blood pressure and heart rate recorded at $4 \mathrm{~min}$ in patients undergoing caesarian section in spinal anesthesia.

Study Design: Quasi experimental study.

Place and Duration of Study: Department of Anaesthesiology, Combined Military Hospital, Malir, from Jul to Dec 2018.

Methodology: The patients were assigned in two groups (A and B) using lottery method. Group A received $0.5 \%$ hyperbaric Bupivacaine solution. Group B received 0.5\% hyperbaric Bupivacaine solution. Spinal anaesthesia was given, blood pressure and heart rate were recorded. Data were analyzed in SPSS version 23. Both groups were compared for mean systolic blood pressure and heart rate by using independent sample t-test.

Results: The mean age of patients was $29.62 \pm 6.21$ years in $0.75 \%$ Bupivacaine group while $29.31 \pm 6.20$ years in $0.5 \%$ Bupivacaine group. The mean systolic blood pressure of patients was $111.63 \pm 5.96 \mathrm{mmHg}$ in $0.75 \%$ Bupivacaine group while $117.16 \pm$ $7.12 \mathrm{mmHg}$ in $0.5 \%$ Bupivacaine group. The difference was significant in both groups ( $p$-value $<0.05)$. The mean heart rate of patients was $92.27 \pm 4.71$ beats per min (bpm) in $0.75 \%$ Bupivacaine group while $97.68 \pm 4.58$ bpm in $0.5 \%$ Bupivacaine group. The difference was significant in both groups ( $p$-value $<0.05)$.

Conclusion: $0.5 \%$ hyperbaric Bupivacaine was better than $0.75 \%$ hyperbaric Bupivacaine solution in spinal anaesthesia during caesarean section.
\end{abstract}

Keywords: Caesarean section, Heart rate, Hyperbaric bupivacaine, Spinal anesthesia, Systolic blood pressure.

How to Cite This Article: Iftikhar H, Aslam A, Rehman HU, Ali Z, Abbass MA, Haider Z. Comparison of Haemodynamic Stability with 0.5\% and 0.75\% Hyperbaric Bupivacaine During Spinal Anaesthesia in Women Undergoing Caesarean Section. Pak Armed Forces Med J 2021; 71(6): $2078-2081$. Doi: https://doi.org/10.51253/pafmj.v6i6.5900

This is an Open Access article distributed under the terms of the Creative Commons Attribution License (https://creativecommons.org/licenses/by-nc/4.0/), which permits unrestricted use, distribution, and reproduction in any medium, provided the original work is properly cited.

\section{INTRODUCTION}

Spinal anaesthesia is one of the anaesthetic modalities used for cesarean section. This technique abolishes sensory and motor functions of several groups of spinal nerves temporarily. The advantages of spinal anaesthesia include rapid onset of action, symmetrical sensory and motor blockade, and cost effectiveness. There is minimal risk of complications related to systemic toxicity due to the small volume sof the anaesthetic used in the procedure. ${ }^{1}$

Bupivacaine is one of the most commonly used drugs for spinal anaesthesia. Spinal anaesthesia is used for any procedure below the umbilicus. ${ }^{1}$ The most common problems associated with spinal anaesthesia include haemodynamic changes such as hypotension and bradycardia. Some of the other problems like nausea, vomiting, and dyspnea are related either directly or indirectly with haemodynamic instability. A successful intrathecal drug should produce adequate extent

Correspondence: Dr Hina Iftikhar, Graded Anaesthetist, Combined Military Hospital, Multan Pakistan

Received: 18 Dec 2020; revision received: 13 Feb 2021; accepted: 15 Feb 2021 and duration of block for proposed surgery without producing undesirable side effects such as profound hypotension and bradycardia. ${ }^{2}$

Baricity of local anaesthesia is an important determinant of the spread of local anaesthetic within subarachnoid space. ${ }^{3}$ Baricity of local anaesthetic can be more (hyperbaric), equal (isobaric) or less hypobaric) than cerebrospinal fluid. A study concluded that hyperbaric Bupivacaine produces adequate sensory and motor blockade at the cost of haemodynamic stability as compared to isobaric Bupivacaine. ${ }^{4}$

A randomized double blind study showed more haemodynamic changes and subject feeling of nausea in hyperbaric group as compared to isobaric group. ${ }^{5}$ Another study showed both hyperbaric and isobaric Bupivacaine produces adequate block without any difference in haemodynamics. ${ }^{6}$

Not much work is done in comparing the hemodynamic effects of $0.5 \%$ and $0.75 \%$ hyperbaric Bupivacaine. There was no international study found by the researcher on the study topic. In Stan study was conducted in year 2009 which compared the haemodynamic 
changes between intrathecal administration of $0.5 \%$ and $0.75 \%$ hyperbaric Bupivacaine in patients undergoing cesarean section under spinal anaesthesia. ${ }^{7}$

In $0.75 \%$ Bupivacaine group mean systolic blood pressure at $4 \mathrm{~min}$ was $109.20 \pm 21.17$ and $0.5 \%$ group was $113.23 \pm 20.27$. For heart rate Mean \pm SD for group I $(0.75 \%) 104.57 \pm 21.90$ and for group $2(0.5 \%) 100.40 \pm$ 18.547 .

In our setup, $90 \%$ of the cesarean sections are done using $0.75 \%$ hyperbaric Bupivacaine. The rationale of this study was to compare the haemodynamic effects of $0.5 \%$ and $0.75 \%$ hyperbaric Bupivacaine so that the superior drug which would produceless haemodynamic effects can be implemented in our setups in the procedure of caesarean section in spinal anaesthesia.

\section{METHODOLOGY}

This quasi-experimental study was conducted at department of Anaesthesiology, Combined Military Hospital, Malir from July 2018 to December 2018. The sample size was calculated by keeping significance level $=5 \%$, power of study $=80 \%$ and anticipated Population mean $=109$ and $S D=20.5,7 n=830$ (415 patients) in each group were equally divided. Patients were enrolled by applying non-probability, consecutive sampling technique as we had to follow the below stated selection criteria.

Inclusion Criteria: All females aged 18-40 years, with American Society of Anaesthesiology (ASA) physical status 1 and 2, undergoing elective caesarean section at term were included.

Exclusion Criteria: Females with any obstetric complication, evidence of fetal compromise, having cardiac, neurological, and spinal disease were excluded.

The patients were assigned in two groups (A and B) using lottery method. Detailed data of patients was collected including age, weight, gestational age and ASA status. Group A received 0.5\% hyperbaric Bupivacaine solution. Group B received $0.5 \%$ hyperbaric Bupivacaine solution. Caesarean section was performed electively in the obstetric operation theatre of Combined Miliatary Hospital Malir under spinal anesthesia. Patients were preloaded with infusion of $500 \mathrm{ml}$ of Ringers lactate solution. Spinal anesthesia was instituted in subarachnoid space at the level of L3-L4 interspace. After the spinal injection, patients were placed in supine position. The trainee recorded the haemodynamic parameters including systolic blood pressure, diastolic blood pressure and heart rate. Blood pressure was monitored by standardized non-invasive blood pressure monitoring and heart rate was recorded by electrocardiogram. The values of systolic blood pressure and heart rate were recorded at $4^{\text {th }}$ min after institution of spinal anesthesia and these variables were filled up on the proforma.

Data were entered and analyzed through Statistical Package for the social sciences (SPSS) version 23. Quantitative variables like age, weight, systolic blood pressure and heart rate were presented as mean and SD. Qualitative variables like ASA status were presented as frequency and percentage. Both groups were compared for mean systolic blood pressure and heart rate by using independent sample t-test. The $p$-value of $\leq 0.05$ was kept as significant.

\section{RESULTS}

In this study, total 830 patients were enrolled with the mean age of patients was $29.62 \pm 6.21$ years in $0.75 \%$ Bupivacaine group while $29.31 \pm 6.20$ years in $0.5 \%$ Bupivacaine group. There was no significant difference in both groups ( $p$-value $=0.471$ ). In $0.75 \%$ Bupivacaine group, there were $254(61.20 \%)$ patients with ASA I and 161 (38.80\%) had ASA II. In 0.5\% Bupivacaine group, there were $258(62.20 \%)$ patients with ASA I and 157 (37.8\%) had ASA II ( $p=0.775)$. The mean weight of patients was $70.66 \pm 10.93 \mathrm{~kg}$ in $0.75 \%$ Bupivacaine group while $68.89 \pm 12.23 \mathrm{~kg}$ in $0.5 \%$ Bupivacaine group ( $p=0.028$ ). The mean systolic blood pressure of patients was $111.63 \pm 5.96 \mathrm{mmHg}$ in $0.75 \%$ Bupivacaine group while $117.16 \pm 7.12 \mathrm{mmHg}$ in $0.5 \%$ Bupivacaine group. The difference was significant in both groups ( $p$-value $<0.001)$. The mean heart rate of patients was $67.47 \pm 4.54 \mathrm{bpm}$ in $0.75 \%$ Bupivacaine group while $77.48 \pm 4.62 \mathrm{bpm}$ in $0.5 \%$ Bupivacaine group. The difference was significant in both groups $p$-value $<0.001$ (Table).

Table: Characteristics of the study groups.

\begin{tabular}{|c|c|c|c|}
\hline \multirow[b]{2}{*}{ Parameters } & \multicolumn{2}{|c|}{ Study Groups } & \multirow[b]{2}{*}{$p$-value } \\
\hline & $\begin{array}{c}0.75 \% \\
\text { Bupivacaine }\end{array}$ & $\begin{array}{c}0.5 \% \\
\text { Bupivacaine }\end{array}$ & \\
\hline No. of Patients & 415 & 415 & \\
\hline Age (Years) & $29.62 \pm 6.21$ & $29.31 \pm 6.20$ & 0.471 \\
\hline \multicolumn{4}{|c|}{ American Society of Anesthesiologists } \\
\hline $\mathrm{I}$ & $254(61.20)$ & $258(62.20 \%)$ & 0.775 \\
\hline II & $161(38.80 \%)$ & $157(37.80 \%)$ & \\
\hline Weight (kg) & $70.66 \pm 10.93$ & $68.89 \pm 12.23$ & 0.028 \\
\hline $\begin{array}{l}\text { Systolic Blood } \\
\text { Pressure }(\mathrm{mmHg})\end{array}$ & $111.63 \pm 5.96$ & $117.16 \pm 7.12$ & $<0.001$ \\
\hline Heart Rate (bpm) & $67.47 \pm 4.54$ & $77.48 \pm 4.62$ & $<0.001$ \\
\hline
\end{tabular}

DISCUSSION

Now-a-day, mostly caesarean sections are done under spinal anaesthesia. ${ }^{8}$ Bupivacaine is commonly 
used for induction of spinal anesthesia during caesarean section. Hyperbaric $0.5 \%$ Bupivacaine and hyperbaric $0.75 \%$ Bupivacaine are two commonly used concentrations of Bupivacaine. Some studies have compared the effects of hyperbaric $0.5 \%$ Bupivacaine with hyperbaric $0.75 \%$ Bupivacaine on hemodynamics and have found no significant differences in both of these drugs and have recommended that $0.5 \%$ Bupivacaine is better than $0.75 \%$ hyperbaric Bupivacaine but on the basis of unclear evidences.7,9 Reduced doses of Bupivacaine can also reduce the occurrence of hypotension and other anesthesia related complications. This low dose of Bupivacaine may also be related to the better maternal cardiac output. 8,10

In our study, the mean systolic blood pressure of patients was $111.63 \pm 5.96 \mathrm{mmHg}$ in $0.75 \%$ Bupivacaine group while $117.16 \pm 7.12 \mathrm{mmHg}$ in $0.5 \%$ Bupivacaine group. There was significant difference between both groups $(p<0.05)$. The mean heart rate of patients was $67.47 \pm 4.54 \mathrm{bpm}$ in $0.75 \%$ Bupivacaine group while $77.48 \pm 4.62 \mathrm{bpm}$ in $0.5 \%$ Bupivacaine group. There was significant difference between both groups $(p<0.05)$. Thus $0.5 \%$ hyperbaric Bupivacaine is superior to $0.75 \%$ hyperbaric Bupivacaine, as the mean systolic blood pressure was near to normal blood pressure range, also the heart rate was near to normal with $0.5 \%$ hyperbaric Bupivacaine as compared to $0.75 \%$ hyperbaric Bupivacaine.

Goyal et al, also found significant difference in systolic blood pressure. In their study, systolic blood pressure after 5 minutes of spinal anesthesia was $109.20 \pm 21.17 \mathrm{mmHg}$ in $0.75 \%$ hyperbaric Bupivacaine patients and $113.23 \pm 20.27$ in $0.5 \%$ hyperbaric Bupivacaine patients. ${ }^{1}$ In $0.75 \%$ Bupivacaine group mean systolic blood pressure at 4 min was $109.20 \pm 21.17$ and $0.5 \%$ group was $113.23 \pm 20.27$. Themean heart rate for group I $(0.75 \%)$ was $104.57 \pm 21.90 \mathrm{bpm}$ and for group $2(0.5 \%)$ was $100.40 \pm 18.54 \mathrm{bpm} .^{7}$

However, another study found that mean systolic blood pressure was $108.30 \pm 22.16 \mathrm{mmHg}$ with $0.5 \%$ hyperbaric Bupivacaine while $112.33 \pm 21.27 \mathrm{mmHg}$ with $0.75 \%$ hyperbaric Bupivacaine. The difference was insignificant ( $p$-value $>0.05)$. Similarly, mean heart rate was $101.50 \pm 19.64 \mathrm{bpm}$ with $0.5 \%$ hyperbaric Bupivacaine while $103.57 \pm 22 \mathrm{bpm}$ with $0.75 \%$ hyperbaric Bupivacaine. The difference was insignificant ( $p$-value $>0.05) \cdot{ }^{9}$

Rai et al, found that after 5 minutes of spinal anesthesia, systolic blood pressure significantly dropped in patients who received $0.75 \%$ hyperbaric Bupiva- caine as compared to patients who received 0.5\% Bupivacaine $107.95 \pm 13.49 \mathrm{mmHg}$ versus $112.76 \pm 11.49$ $\mathrm{mmHg}$, respectively with $p$-value 0.007 . After $10 \mathrm{minu}-$ tes of anesthesia there was no difference in systolic blood pressure in both groups. There was significant difference in heart rate after 10 minutes of anesthesia and decrease in heart rate was more in group II ( $p$ value $=0.006$ ). Nausea, vomiting occurred in $23 \%$ patients in group II and in only $1 \%$ patients in group I. Rescue ephedrine was given in $21 \%$ patients in group I and $35 \%$ patients in group II. Level of block was T6 in $25 \%$ patients in group I and $47 \%$ patients in group II ( $p$-value $=0.001)$. Thus $0.5 \%$ hyperbaric Bupivacainehas less haemodynamic instability and lesschance of bradycardia, less need for rescue ephedrine or nausea and vomiting. ${ }^{11}$

Seyedhejazi et al conducted a trial and observed that the mean $4 \mathrm{mg}$ dose of ephedrine was required for hemodynamic stability with low dose Bupivacaine while $11.75 \mathrm{mg}$ with high dose of Bupivacaine ( $p$-value $=0.006$ ). The mean ratio of least systolic blood pressure achieved during procedure to the systolic blood pressure at baseline was 0.75 in low dose Bupivacaine while 0.65 in high dose Bupivacaine ( $p$-value $=0.04)$. Nausea \& vomiting were observed in $10 \%$ patients in low dose Bupivacaine group while in $20 \%$ patients in high dose Bupivacaine group. Hence, the low dose of Bupivacaine offers a good spinal anaesthesia for caesarean sections with less chances of hypotension, nausea \& vomiting. ${ }^{12}$

However, Rani et al, found that after 60 minutes, the mean heart rate was $76.90 \mathrm{bpm}$ with low dose while $76.20 \mathrm{bpm}$ with high dose, the mean systolic blood pressure was $127.60 \mathrm{mmHg}$ with low dose while $128.32 \mathrm{mmHg}$ with high dose of Bupivacaine and mean diastolic blood pressures was $84.18 \mathrm{mmHg}$ with low dose and $84.24 \mathrm{mmHg}$ with high dose of Bupivacaine. ${ }^{13}$

Another study, conducted by Solakovic et al, the haemodynamic features were compared in $0.5 \%$ hyperbaric versus isobaric Bupivacaine. Findings were statistically significant, showing that the baricity wasvery important effect on behavior of basic haemodynamic characteristics in decreasing the blood pressure and decelerating the pulse rate. Simultaneously, isobaric Bupivacaine showed little deviation in these characteristics. ${ }^{14}$

It has been observed that women undergoing caesarean section and receiving higher doses of Bupivacaine $12-15 \mathrm{mg}$ causing peripheral vasodilatation which may increase the maternal and neonatal morbidity, so 


\section{Haemodynamic Stability}

optimal spinal dose of Bupivacaine has to be sought for prevention of these risks. ${ }^{15-18}$

\section{CONCLUSION}

Thus $0.5 \%$ hyperbaric Bupivacaine was superior to $0.75 \%$ hyperbaric Bupivacaine for spinal anaesthesia during caesarean section. Now in future, we will use $0.5 \%$ hyperbaric Bupivacaine for spinal anesthesia which produces less hemodynamic effects which can be implemented in our setups in the procedure of caesarean section done in spinal anaesthesia.

\section{Conflict of Interest: None.}

\section{Authors' Contribution}

HI: Study design, data collection, AA: Final approval, HUR: Drafting of manuscript, ZA: Tabluation of results, MAA: Literature review, ZH: Critical review, proof reading.

\section{REFERENCES}

1. Goyal A, Shankaranarayan P, Ganapathi P. A randomized clinical study comparing spinal anesthesia with isobaric levo Bupivacaine with fentanyl and hyperbaric Bupivacaine with fentanyl in elective cesarean sections. Anesth Essays Res 2015; 9(1): 57-60.

2. Helmi M, Uyun Y, Suwondo BS, Widodo U. Comparison of intrathecal use of isobaric and hyperbaric Bupivacaine during lower abdomen surgery. J Anesthesiol 2014, Available at: https:// www.hindawi.com/journals/jan/2014/141324/(Accessed on February 20, 2019)

3. Gupta R, Bogra J, Singh PK, Saxena S, Chandra G, Kushwaha JK. Comparative study of intrathecal hyperbaric versus isobaric ropivacaine: A randomized control trial. Saudi J Anaesth 2013; $7(3): 249$.

4. D'Souza AD, Saldanha NM, Monteiro AD. Comparison of intrathecal hyperbaric $0.5 \%$ bupivacaine, isobaric $0.5 \%$ levobupivacaine and isobaric $0.75 \%$ ropivacaine for lower abdominal surgeries. Int J Health Sci Res 2014; 4(1): 22-29.

5. Sia AT, Tan KH, Sng BL, Lim Y, Chan ES, Siddiqui FJ. Use of hyperbaric versus isobaric Bupivacaine for spinal anaesthesia for caesarean section. Cochrane Database Syst Rev 2013; 5(1): CD005143.

6. Punshi GD, Afshan G. Spinal anaesthesia for caesarean section: plain vs hyperbaric Bupivacaine. J Pak Med Assoc 2012; 62(8): 807-810.
7. Sikander RI. Comparison of Haemodynamic, block level and patient comfort by using $0.75 \%$ \& $0.5 \%$ Hyperbaric Bupivacaine in Caesarean Section. Ann Pak Inst Med Sci 2009; 5(4): 259-262.

8. Cenkowski MJ, Maguire D, Kowalski S, Al Gurashi FA, Funk D. Hemodynamic effects of low-dose Bupivacaine spinal anesthesia for cesarean section: A randomized controlled trial. Saudi J Anaesth 2019; 13(3): 208-214.

9. Amjad Q-U-A, Sharif A, Khan A. Comparison of $0.5 \%$ and $0.75 \%$ hyperbaric Bupivacaine given intrathecally in elective lower segment caesarean section. Khyber Med Univ J 2016; 8(2): 79-81.

10. Chooi C, Cox JJ, Lumb RS, Middleton P, Chemali M. Techniques for preventing hypotension during spinal anaesthesia for caesarean section. Cochrane Database Syst Rev 2017; 8(2): CD002251.

11. Rai SA, Malak AM, Ali CA. Comparison between $0.5 \%$ and $0.75 \%$ hyperbaric Bupivacaine given intra-thecally in elective caesarean section. J Postgrad Med Inst 2018; 32(1): 87-90.

12. Seyedhejazi M, Madarek E. The effect of small dose Bupivacainefentanyl in spinal anesthesia on hemodynamic nausea and vomiting in cesarean section. Pak J Med Sci 2007; 23(5): 747.

13. Rani $Z$, Mehmood $T$, Ishrat Z. Comparison of efficacy and hemodynamic effects of two different concentrations of hyperbaric bupivacain $0.5 \%$ and $0.75 \%$ during spinal anesthesia. Pak J Med Health Sci 2019; 13(3): 659-664.

14. Solakovic N. Comparison of hemodynamic effects of hyperbaric and isobaric Bupivacaine in spinal anesthesia. Med Arch 2010; 64(1): 11-15.

15. Zahir J, Hussain T, Qureshi Q, Rehman H. Level of block achieved with $1.6 \mathrm{ml}$ of $0.75 \%$ Bupivacaine along with the hemodynamic variations after spinal anesthesia: a prospective study among Pakistani women undergoing elective caesarean sections. Ann Pak Inst Med Sci 2013; 9(2): 88-90.

16. Abdollahpour A, Azadi R, Bandari R, Mir Mohammad Khani M. Effects of adding midazolam and sufentanil to intrathecal Bupivacaine on analgesia quality and postoperative complications in elective cesarean section. Anesth Pain Med. 2015; 5(4): e23565.

17. Kinsella S, Carvalho B, Dyer R, Fernando R, McDonnell N, Mercier F, et al. International consensus statement on the management of hypotension with vasopressors during caesarean section under spinal anaesthesia. Anaesthesia 2018; 73(1): 71-92.

18. Ünlügenç $H$, Turktan $M$, Evruke İC, Gündüz $M$, Burgut $H R$, Yildıztaş HY, et al. Rapid fluid administration and the incidence of hypotension induced by spinal anesthesia and ephedrine requirement: the effect of crystalloid versus colloid coloading. Middle East J Anaesthesiol 2015; 23(3): 273-281. 